Fake-News ! Pouvoirs et conflits autour de l'énonciation publique du « vrai »

\title{
Widad Mustafa El Hadi : Fondements épistémologiques et théoriques de la science de l'information- documentation
}

Édouard Laroche-Joubert

\section{OpenEdition}

\section{Journals}

Édition électronique

URL : https://journals.openedition.org/edc/9602

DOI : 10.4000/edc.9602

ISSN : 2101-0366

Éditeur

Université de Lille

Édition imprimée

Date de publication : 15 décembre 2019

Pagination : 217-219

ISBN : 978-2-917562-22-2

ISSN : $1270-6841$

\section{Référence électronique}

Édouard Laroche-Joubert, « Widad Mustafa El Hadi : Fondements épistémologiques et théoriques de la science de l'information-documentation », Études de communication [En ligne], 53 | 2019, mis en ligne le 15 mars 2020, consulté le 08 janvier 2022. URL : http://journals.openedition.org/edc/9602 ; DOI : https://doi.org/10.4000/edc.9602

Ce document a été généré automatiquement le 8 janvier 2022

() Tous droits réservés 


\title{
Widad Mustafa El Hadi : Fondements épistémologiques et théoriques de la science de l'information-documentation
}

\author{
Édouard Laroche-Joubert
}

\section{RÉFÉRENCE}

Mustafa El Hadi W. (dir.) (2018). Fondements épistémologiques et théoriques de la science de l'information-documentation. Actes du 11e colloque ISKO France 2017, Londres, ISTE Editions.

$1 \mathrm{Au}$ sein de la $71^{\mathrm{e}}$ section du Conseil national des universités, les Sciences de l'information et de la communication - spécificité française -, il est souvent difficile de se repérer et de prendre la mesure de la part que les Sciences de l'information y occupent. L'ouvrage, dirigé par Mustafa El Hadi, permet d'y remédier : les actes du onzième colloque d'ISKO-France en dresse, sinon une cartographie complète, du moins un vaste panorama de ses racines francophones. Il regroupe en effet les textes des communications présentées lors de ce onzième congrès organisé, entre autres, par Widad Mustafa El Hadi, Professeure à l'Université de Lille, co-fondatrice et plusieurs fois présidente du Chapitre Français de l'ISKO (International Society for Knowledge Organization), la société internationale pour l'organisation des connaissances, qui s'est tenu au siège de l'UNESCO à Paris.

2 Trente-quatre articles, écrits ou coécrits par soixante-deux auteurs, offrent un panorama varié des fondements des Sciences de l'information, explorant l'histoire de la discipline, en France et dans les pays francophones, de sa fondation et de son établissement, à travers les travaux des premiers penseurs et l'influence qu'ils exercent encore aujourd'hui sur ceux des chercheurs comme des professionnels de notre discipline. Organisé en quatre parties, l'ouvrage permet d'aborder les approches théoriques et épistémologiques de la Science de l'information-documentation dans la première, où l'on retrouvera neuf articles exposant des regards variés sur les travaux 
des pionniers de l'établissement historique de la discipline, puis la seconde offre un état des lieux de l'impact des auteurs francophones, que ce soit en France ou dans le monde et où l'on découvrira quelques figures méconnues de la documentation, la troisième partie étant consacrée à l'empreinte de Paul Otlet, regroupant de nombreux articles sur le premier documentaliste de l'histoire, et la quatrième partie aux concepts, méthodes et outils pour l'organisation des connaissances, exposant un état des lieux de la recherche actuelle en Sciences de l'information et de l'inspiration que les chercheurs puisent dans l'œuvre de leurs prédécesseurs, que ce soit à travers des tendances scientifiques, des concepts théoriques, des outils de recherche ou des cas concrets d'études se fondant sur le cadre théorique élaboré par les pères de la discipline. La diversité des auteurs, soulignée dans la préface, tant Français qu'internationaux, notamment Belges, Brésiliens, Bulgares, Danois, Espagnols, Portugais, Polonais, Italiens, Américains, Canadiens, etc., et les langues des articles, certains français, d'autres anglais, montrent l'importance des pionniers francophones dans l'histoire des Sciences de l'information.

On y (re)découvrira tout autant des figures de théoriciens que de praticiens, professionnels de la documentation ou des bibliothèques, voire scientifiques ayant œuvré à la documentarisation de leur domaine et, ce faisant, ayant contribué à l'avancée de l'organisation des connaissances et des Sciences de l'informationdocumentation. Outre les pionniers les plus classiques et reconnus de notre domaine, tels que Paul Otlet, Suzanne Briet, Jean Meyriat, Jean-Claude Gardin, on y rencontrera aussi, au détour des pages, des références moins connues du public, tels que Jacques Maniez, pourtant penseur important de l'information-documentation, Louise-Noëlle Malclès, experte de la catalographie, parfois inattendus, comme la figure d'Eugène Morel, écrivain et grand rénovateur des bibliothèques du début $d u x^{e}$ siècle, voire des auteurs « transfuges » d'autres disciplines, à l'instar des sociologues Émile Durkheim et Marcel Mauss, ou encore Jacques-Émile Dubois, chimiste ayant éminemment contribué à l'information scientifique et technique (IST) en France. Et si l'on regrettera l'invisibilité au sommaire d'autres grands pionniers, comme Gabriel Naudé, Auguste Comte, Robert Escarpit, Robert Pagès, ou encore Éric de Grolier, on s'enthousiasmera à l'évocation assez étendue que l'ouvrage nous offre de l'impact dans le monde actuel de grands penseurs de l'histoire de notre discipline: cette découverte ou redécouverte avec les racines des sciences de l'information-documentation conviendra tout autant aux jeunes étudiants qui découvriraient la discipline qu'aux chercheurs aguerris qui y trouveront matière à renouveler leurs réflexions épistémologiques et théoriques.

\section{AUTEURS}

\section{ÉDOUARD LAROCHE-JOUBERT}

Univ. Lille, EA 4073 - GERiiCO, F-59000 Lille, France

edouard.laroche-joubert@univ-lille.fr 